\title{
Teaching BIM as a collaborative information management process through a continuous improvement assessment lens: a case study
}

Article

Accepted Version

Nikolic, D., Castronovo, F. and Leicht, R. (2021) Teaching BIM as a collaborative information management process through a continuous improvement assessment lens: a case study. Engineering, Construction and Architectural Management. ISSN 0969-9988 doi: https://doi.org/10.1108/ECAM-11-20201000 Available at https://centaur.reading.ac.uk/98829/

It is advisable to refer to the publisher's version if you intend to cite from the work. See Guidance on citing.

To link to this article DOI: http://dx.doi.org/10.1108/ECAM-11-2020-1000

Publisher: Emerald

All outputs in CentAUR are protected by Intellectual Property Rights law, including copyright law. Copyright and IPR is retained by the creators or other copyright holders. Terms and conditions for use of this material are defined in the End User Agreement. 


\section{CentAUR}

Central Archive at the University of Reading

Reading's research outputs online 


\title{
Teaching BIM as a collaborative information management process through a continuous improvement assessment lens: a case study
}

\author{
Dragana Nikolić \\ University of Reading, $U K$ \\ Fadi Castronovo \\ University of Brighton, $U K$ \\ Robert Leicht \\ The Pennsylvania State University, US
}

\begin{abstract}
Purpose - This study explores a pedagogical approach to teaching students a collaborative information delivery process. Its objectives are to understand how students address the complex and open-ended challenge of planning this process and to identify strategies for improvement through a reflective plan-do-check-act cycle and reflection.

Design/methodology/approach - We present a longitudinal case study grounded in qualitative data gleaned from three consecutive years of teaching a senior undergraduate construction engineering course.

Findings - The findings illustrate a rich picture of how students navigate this challenge and emphasize the complex nature of teaching BIM as an information management process. We present examples of how students learn to understand BIM standards by engaging in relevant experiences. The findings also demonstrate the value of an outcome-based approach that fosters understanding through an iterative plan-do-check-act cycle in which a BIM execution plan (BEP). Practical implications - This research contributes knowledge about mechanisms that support students in planning, managing and improving collaborative information strategies in a BIM context. Specifically, we illustrate a tension between teaching industry-oriented process planning methods and making them relevant to students for effective engagement in interdisciplinary teams.

Originality/value - We argue that teaching students to plan, design and execute a BIMembedded collaboration information delivery process can be firmly nested within teaching management and communication skills. We illustrate how students can understand BIM approaches by making them concrete and meaningful to their own experience.
\end{abstract}

Keywords: Problem-based learning, BIM, construction education, collaboration, information management. 


\section{Introduction}

Both in the UK and globally, the construction industry has been tasked with improving the efficiency of project delivery and generating value for clients. This push for significant continuous improvement is coupled with growing initiatives for structuring project delivery practices, such as building information modeling (BIM) methods, and has shifted the emphasis onto the structured data sets at every project stage. In the UK, the most recent concerted effort to improve construction practices came in April 2016, when a government mandate required the design and construction industry tendering for publicly-procured work to comply with the BIM standards, methods, and protocols published in several BIM documents. Since then, this mandate has assumed a more advisory role in line with the international BIM standard (the ISO 19650 series) superseding the suite of British standards (the BS 1192 series), which exemplifies the continued global effort to advance project delivery processes.

However, specific implementation mechanisms notwithstanding, the overarching aim of these initiatives is to reduce waste and uncertainty and to guide the industry in increasing the accuracy, completeness, and usability of information through the activity stream. And while BIM tools and technologies have to date largely dominated the conversation around improving information delivery practices, some emphasis has now shifted to collaboration around shareable data (Landscape Institute 2016). In this context BIM is primarily understood as a structured process in which BIM technology and 3D models serve only as a means for achieving an integrated and highly coordinated delivery process. For example, published British standards such as the BS1192 series and specifically the code of practice BS1192:2007 + A2:2016 (now superseded by ISO19650 ${ }^{1}$ ) outline methods and procedures for collaborative production and management of asset information across all life cycle stages.

Thus the implication of these standards and methods constitutes a shift in focus from technology to information management, coordination and teamwork where the goal is to have the right information, at the right time. However, when faced with teaching students how to apply these standards and methods, one challenge is that their adoption have been slow and inconsistent, due to, among other things, an overwhelming need to upskill the existing practice community in how to properly apply them on projects. Studies have reported that in addition to managing technological change, among the greatest barriers to adopting BIM involve training and building skills for collaborative work (Abdirad and Dossick 2016; Ku and Taiebat 2011). This in turn presents educators with the task of arming graduates with both relevant domain knowledge and collaborative problem-solving skills (Koutsabasis et al. 2012; Kronholm 1996).

Although most of the literature suggests that construction engineering and management students have little difficulty acquiring software-related skills, the development of the strong communication and teamwork skills deemed essential to applying knowledge in practice has been somewhat less scrutinized (Fruchter 2001; Kalay 2001; O’Brien et al. 2003). Moreover, the BIM process, which is shaped by a range of technologies and tools, presents a long-standing pedagogical concern for students to not only learn to use software, but also evaluate and select the

\footnotetext{
${ }^{1}$ https://www.iso.org/standard/68078.html
} 
most appropriate use and resource management strategies (Witmer 1998). Thus, students are now not only tasked with learning software, but also expected to develop skills related to process planning and production management in digital contexts in order to contribute to integrated design and construction teams. In other words, as Henderson and Jordan (2009) argued, future professionals should learn data management, information technology, and systems thinking situated within a collaborative design process, and the education of building professionals should follow that of inclusive liberal arts curricula to better capitalize on the "constructive, creative and social nature of building and learning" [p36].

This suggests that under the BIM paradigm of collaborative working, traditionally taught discipline-specific skills are insufficient, and the emphasis should instead shift to a more complex and flexible set of skills, such as thinking independently, managing ambiguity, solving complex problems, and adapting to changing practices (Henderson and Jordan 2009; Shelbourn et al. 2017). However, this multifaceted knowledge and epistemological development is significantly more challenging to impart and assess using traditional teaching approaches. To address some of these challenges, a growing body of research suggests that teaching students in experiential learning environments supported by continuous assessment and improvement methods can advance problem-solving and decision-making skills. Thus, the development and adoption of BIM in conjunction with lean collaborative processes presents an opportunity to engage students in an iterative process of solving problems and collaborating on projects that foster the development of much-needed collaboration strategy skills.

\section{Background}

\subsection{Approaches to BIM process planning}

A broad body of literature discusses the range of BIM aspects seen to offer solutions to inefficiencies in how information is authored, shared, and used in design, construction, and operations. A series of UK government-funded reports produced between the 1970s and late 1990s (e.g. Crawshaw 1976; Egan 1998; Latham 1994) gave way to a government strategy that defined BIM maturity levels with the mandate to use BIM Level 2 on all publicly procured projects as of April 2016 (Cabinet Office 2011). In the meantime, "BIM Level 2" as a maturity indicator gave way to the information management framework known as the "UK BIM Framework" , though the principles remained essentially the same. While one could debate the extent of BIM adoption since the mandate was introduced (Dainty et al. 2015), the focus remains on the role of information in the project delivery process and the transparency in how it is shared and used. Regardless of whether we talk about BIM levels or the current BIM framework, implementing BIM involves a number of required and voluntary measures for developing a structured process in an effort to decrease industry fragmentation in terms of information sharing. Essentially, BIM is a file-based collaboration and library management within a centrally

\footnotetext{
2 https://ukbimframework.org/
} 
coordinated data environment, where the role of an information manager becomes key in ensuring that the correct and purposeful information is available to those who need it when they need it.

In this context, the implications for teaching BIM lie in a gradual shift in emphasis from digital models as sources of knowledge (National Institute of Building Sciences 2007) toward "value creating collaboration" (UK BIM Task Group 2014) and "collaborative way of working, underpinned by the digital technologies," (HMGovernment 2012). While the purported benefits of using BIM span disciplines and scopes of implementation, from a collaboration standpoint, BIM is still regarded as a facilitator of concurrent rather than sequential information workflows and more integrated tasks through a shared (3D) model (Becerik-Gerber et al. 2012). This approach, in turn, requires planning of information management and team coordination activities, typically documented in what is known as a BIM execution plan (BEP). A BEP documents client and stakeholder goals and project requirements, as well as the standards, methods, and procedures in authoring, sharing, coordinating, and delivering information. In the UK, standards such as BS1192:2007 + A2:2016 and publicly available specifications, such as the PAS1192 series (all now superseded by ISO19650 with national annexes), prescribe methods for structuring the common data environment (CDE) as a single source of truth. The purpose of a CDE and standardized file naming conventions is to minimize errors from duplication, incorrect file versioning, and the use of information for purposes other than indicated. From the perspective of lean thinking (e.g. Tribelsky and Sacks 2010) these are sources of wasted information, time, and resources. Thus, through employing explicit file and task management strategies, the intent is to encourage early and ongoing conversations among project team members to plan for seamless information exchange.

Internationally, and especially in the US, similar objectives were addressed in the BIM Project Execution Planning Guide (Messner et al. 2020). While less prescriptive, the guide offers a structured procedure for teams to customize their information management and delivery processes based on goals and pursued value streams. Again the intent here is to assist early project planning by encouraging discussion on the scope of BIM implementation on the project, the impact and implications of the process, and gathering team skills and infrastructure capabilities. The guide also provides templates for documenting BIM uses, information exchanges and process maps at the project- and task-levels. Finally, the guide has been implemented in teaching undergraduate and postgraduate students process-mapping activities and interdisciplinary collaboration (Ayer et al. 2015; Holland et al. 2010; Solnosky et al. 2015).

The core principle behind these BIM initiatives is to encourage project teams to plan and document their strategy early in the form of a BEP by defining the end outcome and then identifying information requirements to make the processes purposeful and value-driven. The value- or pull-driven principles of having 'the end in mind' have aligned BIM with the principles of lean thinking, which seek to identify and reduce waste (Womack and Jones 1997), or more specifically focus on information flow and ways to measure and improve it (e.g. Dubler 2011; Koskela 2000; Sutrisna and Goulding 2019). Perhaps most important, the continuous pursuit of improvement behind lean thinking, which implies the iterative nature of planning, evaluating, reflecting, and adjusting the process, is what is also the intention behind BIM implementation in which BEP serves as a living document that is continuously updated to reflect the dynamism in process variability and uncertainty. These initiatives have presented both industry practitioners 
and educators with two complex tasks: how to employ the existing tools and methods to effectively plan and map information management processes and how to identify and address inefficiencies in order to improve these processes.

\subsection{Pedagogy around teaching BIM-enabled collaboration}

Identifying a problem, evaluating options, and making decisions in collaborative settings are all necessary skills for students in the AEC disciplines. The design and construction fields are dynamic and dominated by complex, ill-defined problems with many possible solutions (Dossick and Neff 2011). Planning a collaborative project delivery in a BIM context is a complex process that considers the project context, scope, goals, information requirements, information exchanges, resources, technologies, and other contingencies for delivering the requested information. Learning to efficiently plan these processes presents students with plenty of managerial challenges. Studies have examined these pedagogical challenges by considering questions of soft skills such as leadership, interdependence, social communication, and teamwork in both collocated and remote settings (Fruchter 2003; Sancho-Thomas et al. 2009) as well as supporting information technology needs.

Problem-based and experiential learning have been recognized as valuable approaches to immersing students in realistic scenarios for teaching the complexity and ill-structured nature of BIM-enabled collaboration. For example, Wu and Hyatt (2016) used a problem-based learning in a solar house design competition where they tasked students with using BIM tools for producing a set of construction documents. However, here BIM was primarily defined as the use of 3D and cost-based modeling, as well as 4D schedule simulation.

Other studies have explored ways to teach students to use BIM on projects by employing the existing guidelines and standards. For example, Beauregard et al. (2016), investigated student understanding of project execution planning techniques, particularly in terms of roles and responsibilities when developing project-level (i.e. Level 1) and task-level (i.e. Level 2) process maps. While the peer-review nature of this short class activity did not offer long-term insight into how students approach and process such complex tasks, the findings suggested that the concept of information exchange remains quite abstract for many students due to their lack of experience. Similarly, Bozoglu (2016) detailed the implementation of several BIM learning modules that promote the development of collaborative skills using a BIM Project Execution Planning Guide (Messner et al. 2020) as a coordination strategy. Ambitious in their range of aimed competencies, these modules still center on the use of technology as a learning tool. Furthermore, while the study adopted Kolb's (1984) experiential learning cycle, it does not offer greater insight into the reflective dimension of student experience.

There have also been attempts to identify competencies and synthesize pedagogical approaches into more comprehensive frameworks for teaching collaborative BIM processes (Macdonald 2012; Succar and Sher 2014). Rahman et al. (2019) suggested a BIM course development framework for helping students to build social and process-related management skills, such as communication, planning, and teamwork. This framework begins to emphasize non-technical skills as important, though it was developed for a single session and was not actually implemented to offer evidence of educational benefits. 
Thus, approaches to teaching BIM remain as diverse as the topic itself. The growing consensus around moving beyond teaching technology decoupled from practical interdisciplinary and collaborative contexts emphasizes the need for self-directed learning and epistemological development in problem-based settings. While many studies have explored the new computing tools skills and the dynamics of file-sharing and collaboration, few have investigated how teaching related to integrated processes can best engage students in advancing their metacognitive and epistemological development. Epistemological development, or epistemic cognition, concerns the ability to understand the nature of a given problem and decide on appropriate problem-solving strategies (Kitchner 1983). Perry (1999) described this process as how a person makes sense of knowledge as they are challenged with meaning in both philosophical and technical areas. As Salner (2011) pointed out in her framing of systems thinking, this development is associated with placing students in a position or environment that pressures them to synthesize and reflect on their own cognitive patterns. This type of 'pressure' aligns with the common employment of project-based learning in construction management curricula. Additionally, to support students in reflecting on their own cognitive patterns, instructors are encouraged to adopt their own continuous improvement strategies based on lean methods.

\subsection{Continuous Improvement in Construction and Education}

One of the founding principles of the Toyota Production System's concept of lean manufacturing is continuous improvement (Forbes and Ahmed 2011). Seed (2015) defined continuous improvement as an environment in which people are encouraged to experiment and potentially fail as long as their goal is to improve. To foster continuous improvement, the Lean Construction Institute (LCI) suggests that teams map the value stream of their business practices in order to determine base metrics of time, costs, safety, and quality (Seed 2015). During this mapping process, teams should identify areas where waste, as defined in the lean literature, can be eliminated from the process. The LCI also suggests methods for identifying waste and driving continuous improvement, such as Plus/Delta sessions, the "5 Whys" analysis procedure and Plan Do Check and Adjust (PDCA) evaluation cycles. As Forbes and Ahmed (2011) described, during a Plus/Delta analysis, a team lists in two columns the factors that have produced value (i.e. Plus) and those that might produce higher value (i.e. Delta). In the " 5 Whys" procedure, team members repeatedly ask "why" to identify the root cause of an issue (Forbes and Ahmed 2011). Lastly, in a PDCA evaluation cycle, a team proposes a solution to a problem, enacts it, evaluates if the problem has been solved, and then adjusts any processes that are not bringing it value.

In the education field, the concept of continuous improvement has been equally deemed as valuable in its aim of achieving systematic improvement through incremental changes in teaching, learning, and research (Morris and Hiebert 2011; Tichnor-Wagner et al. 2017). At the core of the educational continuous improvement literature is the Plan Do Study Act (PDSA), a variant of the PDCA method described above (Deming 2018). Similar to PDCA, the PDSA cycle focuses on rapid learning from iterative loops that are focused on identifying changes. The method has allowed institutions to improve the quality of mathematics pedagogy at administrative and instructional levels (Cobb et al. 2013), and to increase the graduation rates of mathematics high school students (Hoang et al. 2017). In engineering education, accreditation bodies, such as 
the Accreditation Board for Engineering and Technology (ABET) have adopted continuous improvement approaches as an important element of their assessment criteria (Christoforou and Yigit 2008; Prados et al. 2005). Continuous assessment is also part of educational continuous improvement theory and focuses on an ongoing assessment process whereby learners are given frequent feedback and evaluations on assignments (Hernández 2012; Isaksson 2008; Trotter 2006). Implementation of the continuous assessment model has shown improvements in both teaching and learning in engineering education (Christoforou and Yigit 2008; Tuunila and Pulkkinen 2015). For example, Cole and Spence (2012) found significant increases in student engagement and improved test performance after implementing a continuous assessment model in civil and mechanical engineering courses.

Thus the benefits of implementing continuous improvement in lean construction parallel those of continuous assessment in education. Continuous assessment methodologies do not only apply to courses that cover lean topics, but also to those that can benefit from fast feedback cycles, based on PDSA/PDCA. Implementing continuous improvement strategies in construction education can integrate the technological skills associated with using BIM into process planning and management methods through iterative evaluation and reflection. For this study, we applied the continuous assessment to support the achievement of learning objectives, increase student engagement, and improve course quality with respect to the more abstract elements of implementing BIM as a lean process.

\section{Method}

The primary question we addressed in this study involves how to teach students collaborative project information delivery in a global BIM context by focusing on what makes team collaboration effective, while managing the challenges of creating a comparable experience in the classroom. To illustrate some of the pedagogical challenges involved in teaching collaborative BIM approaches, we discuss our experience teaching three consecutive years of a senior-level elective undergraduate construction management course. Specifically, we were interested in exploring a pedagogical approach to engaging students in a metacognitive problem-solving process in identifying the tasks, goals, resources and other considerations involved in implementing BIM through planning their assignment delivery process and reflecting on the outcomes. We approached this course by adopting the previously discussed continuous improvement principles.

The course applied the techniques of self-directed, research-driven and reflective learning experiences in the context of a semester-long group project. The primary goal of the course was to identify the challenges involved in collaborating across various disciplines and project teams that use a range of technology, information formats, exchanges, and management methods.

We employed ethnographic research methods to collect data over the three-year period, including observations of group discussions and informal conversations, document analysis of initial and updated BIM execution plans, team self-assessment surveys and student reflections on the collaborative process. Study participants included 85 students from architecture, quantity surveying and construction management disciplines (25 students in 2018, and 30 students in 2019 
and 2020 respectively). In the following sections, we discuss the course project setup, the learning objectives and the pedagogical strategies.

\subsection{Course structure and learning objectives}

The third-year undergraduate elective course involved in this study introduces students to BIMbased project delivery methods by focusing on how to plan, manage, coordinate and communicate team-based information delivery. To achieve this goal, we grounded the course in both constructivist (Brooks and Brooks 1999) and lecture-based methods and structured it around four components: 1) a semester-long group assignment; 2) lectures and team consultations with the instructor, 3) short self-paced software tutorials to support the practical work, and 4) an individual reflective report (Figure 1). Above all, we planned this structure to emphasize the importance of constructive group dynamics, self-guided learning and resourcefulness in addressing complex problems.

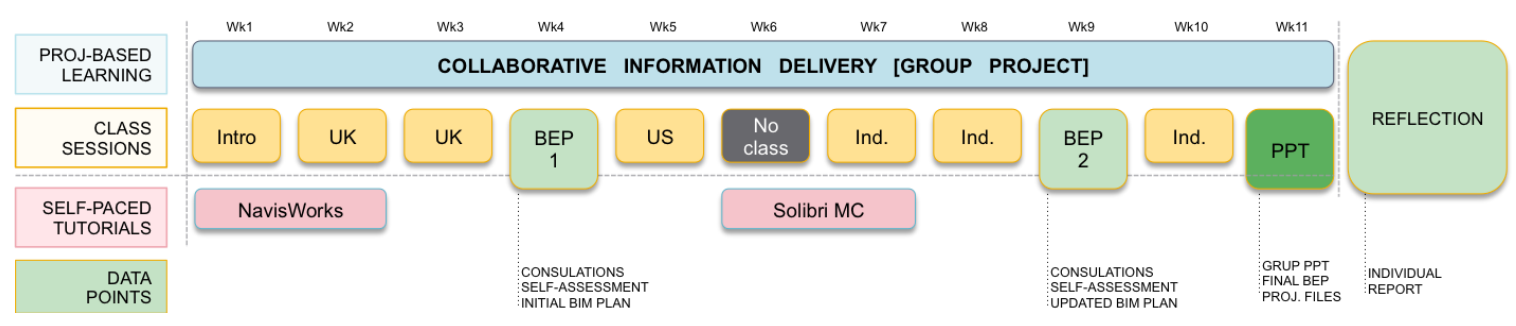

Figure 1: The course structure outlining the three layers of content and data collection points

The central course component was the group assignment, which challenges student teams to design and evaluate a collaborative project delivery process. This task is incredibly complex as it requires students to 1) identify the components of this process (e.g. tasks, activities and deliverables); 2) estimate and plan all of the resources to complete this process (e.g. skills, responsibilities, time, technologies) and 3) document the process as a BEP that is meaningful and clear to the teams. While a few investigations on the use of BIM execution plans in teaching reported various challenges, such as a limited understanding of developing process maps (e.g. Beauregard et al. 2016), little is known about how students learn to understand the rationale behind the BEP content.

For most students, while developing a BEP is complex enough, the subsequent steps of implementing, monitoring, evaluating, and improving these plans is what makes this exercise essentially what is known as an ill-defined problem. Ill-defined problems are widely recognized as those that do not have a single solution, but rather can be addressed in many possible ways deemed as more or less optimal. Generally, educational research in engineering suggests that illdefined problems can be addressed through project- or problem-based work (Perrenet et al. 2000). Both learning approaches are similar in that they present students with open-ended or "messy" real-world challenges which they try to solve by working in small groups and reflecting on their experience (Hmelo-Silver 2004; Walker et al. 2015). 
In sum, the course project asked student teams to deliver a well-defined product (i.e. specific project information) by following an ill-defined process (i.e. BIM-compliant collaboration practice). In previous years, the approach to teaching BIM resembled similar initiatives that used BIM templates and execution planning guides as frameworks for teams to document their strategy. However, a recurring challenge in teaching the course this way was the realization that simply following BEP templates was insufficient for students to understand the purpose of various sections and requirements, and largely resulted in what was akin to a box-ticking exercise. In addition, as guest speakers from industry and academia often discussed conflicting views of related practices and concepts, for students accustomed to well-structured problems with defined solutions, these conflicts often became challenging.

Thus, we were motivated to revise the course approach in order to change the tendency of students to perceive group work as a sum of individual inputs and to refocus on building collaborative skills, such as communication, negotiation and team management. In light of these observations and past experiences teaching the course, we retooled our content to address the following learning objectives:

1. Identify goals, tasks and resources necessary for constructive collaboration;

2. Build collaborative and communication skills for negotiating and allocating responsibilities, assigning tasks, monitoring progress, supporting and managing teams;

3. Use technologies as appropriate for respective tasks; and

4. Evaluate and reflect on the applied strategies, decisions and performance to evaluate team collaboration and applicability of BIM guidelines in informing the process.

The project work was supported by a series of industry speaker lectures that introduced students to the guiding principles and methods outlined in both UK standards (e.g. BS1192) and US BIM guidelines (i.e. BIMex); concepts of interoperability and open-BIM initiatives such as IFC and COBie, and innovation in digital and collaborative work practices (as outlined in Figure 1). We also dedicated two class sessions for instructor-led team consultations to check project progress, review the BIM plans and address questions.

\subsection{Project assignment and formation of teams}

In 2018, the first year of the teaching reported in this study, all course students were from construction management and engineering. In the following two years, 2019 and 2020, architecture students joined the course, in numbers to comprise approximately half of the course. While this change increased the diversity of student disciplines and skills in the course, it also called for a different approach to populating the student teams. In 2018, given that the students shared a program and thus knew each other reasonably well, we allowed them to self-organize into teams of 4-5 members. However, in the following two years we took a mixed approach to encourage students from different programs to work across disciplines and not exclusively gravitate toward their familiar peers. To support this team diversity, enrollment was done in two steps. First, we allowed students to self-select into teams of two for a short classroom task. Then, we randomly paired these self-selected teams into larger cross-disciplinary project teams.

For a project to serve as a practical platform for the collaborative work, we chose a West Riverside hospital design model from Autodesk's resources site that we modified to suit our 
learning objectives. We chose this model because: 1) it contained a broad range of discipline models to illustrate the extent of cross-disciplinary collaboration and coordination of systems; 2) it was sufficiently complex in terms of level of building systems detail; and 3) it contained examples of a number of common coordination issues and clashes the teams had to avoid when designing and planning their coordination. Each team received a set of project exchange files in IFC and Revit formats, including architectural, structural, mechanical, plumbing, electrical, fire, and sprinkler system models (Figure 2).

The models were then modified to remove all the building systems from a single fourth-floor wing that we then asked students to complete by applying a coordinated strategy and avoiding the known issues they would find in other wings. Specifically, students were encouraged to consider how to collaborate effectively by completing tasks that included: 1) performing an initial model check and clash analysis to identify problems in the existing design; 2) defining goals, tasks and responsibilities for completing the incomplete hospital wing; and 3) developing a BEP to capture aspects of the collaboration and information management process in the first two tasks.

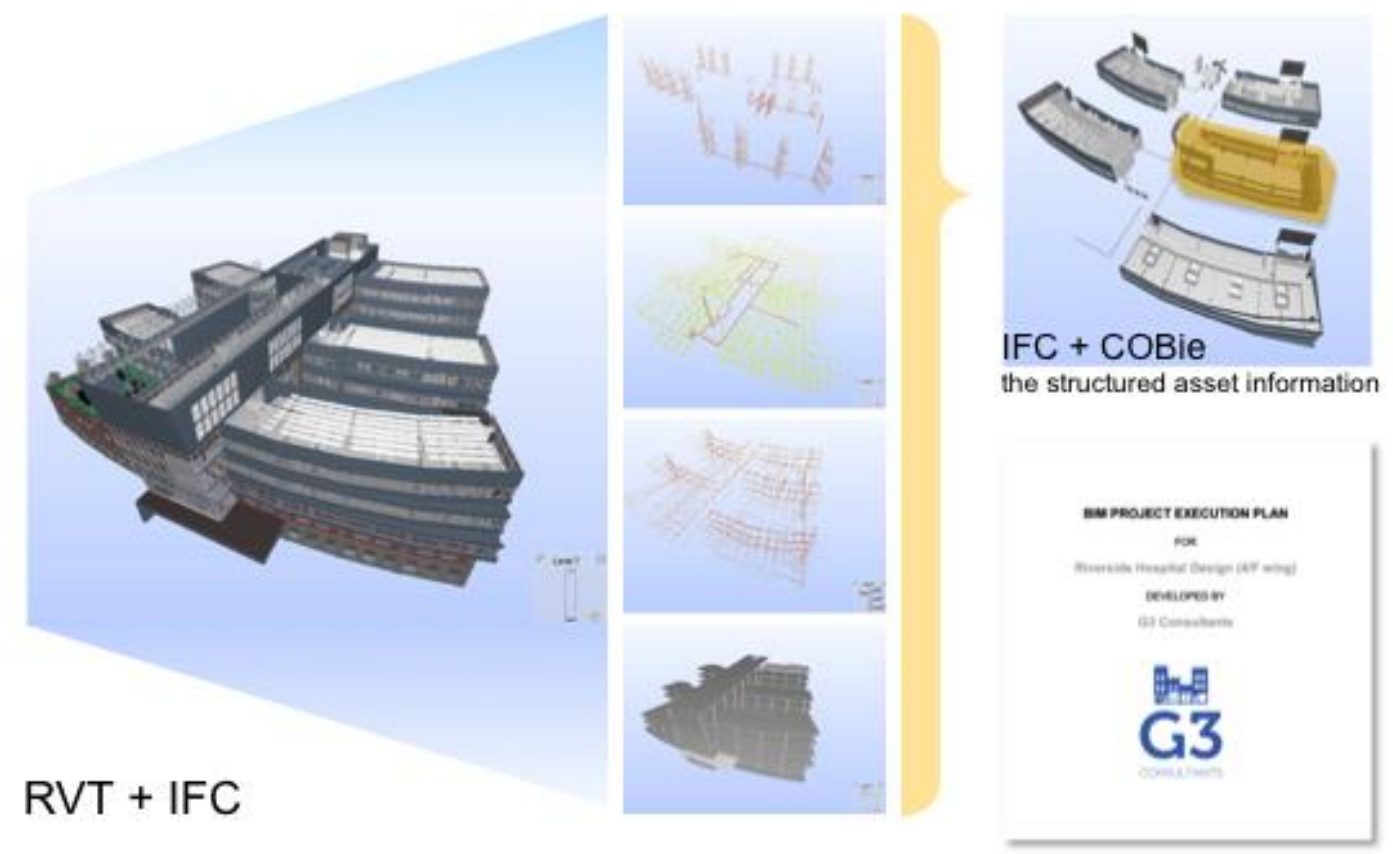

Figure 2: Images capturing discipline-specific models of a hospital project that the student teams received (left), and the deliverables including the federated model of a floor wing and the collaborative BIM execution plan.

Modeling a single floor wing of a hospital project served as a practical, manageable and sufficiently challenging exercise for the teams to develop, test and improve their collaborative strategies. Our intention was to balance the complexity of planning a collaborative process with an appropriate amount of modeling and analysis. And while we did not require students to use any particular software applications, we did expect them to have basic digital modeling skills. We 
advised the students to discuss the technical skills they brought to their respective teams and to devise an initial strategy they deemed most effective. Given that the software skill levels varied significantly among the students, we also took measures to ensure that whatever modeling was required did not fall on the few skilled members.

For each year, we began the course by spending the first three weeks introducing students to UK and US BIM initiatives and standards, sharing the goal of reducing process and information waste. Given that planning this process is largely context-based and custom-designed, for our purposes, this meant encouraging students to cycle through stages of defining the goals, identifying and applying strategies, and reflecting on the outcomes in order to update and improve these strategies. To help students navigate this process, we suggested a loose timeline for major tasks and deliverables with suggested resources (Table 1).

Table 1: Suggested project task timeline with process-based (green) and model-based (purple) tasks with two client-team meetings in Weeks 4 and 8

\begin{tabular}{|c|c|c|c|c|c|c|c|c|c|c|}
\hline - & 1 & 2 & 3 & 4 & 5 & 6 & 7 & 8 & 9 & 10 \\
\hline $\begin{array}{l}\text { Team formation, roles and } \\
\text { responsibilities allocation } \\
\text { (refer to BIMex or BEP) }\end{array}$ & \multicolumn{10}{|c|}{$\begin{array}{l}\text { Agree roles with defined responsibilities in the project team. Some } \\
\text { responsibilities may not be discipline-specific, or may be shared among } \\
\text { team members (e.g. checking information for completeness, correctness) }\end{array}$} \\
\hline $\begin{array}{l}\text { *Preliminary } \\
\text { collaboration (BIM) plan } \\
\text { (e.g. BIMex, Sec. F-; Post- } \\
\text { contract BEP, Sec.4.4) }\end{array}$ & \multicolumn{10}{|c|}{$\begin{array}{l}\text { Develop an initial (BIM Execution) plan for collaborative working. Define } \\
\text { general project and discipline-specific tasks with planned durations. Define } \\
\text { information exchange workflows. }\end{array}$} \\
\hline $\begin{array}{l}\text { Information management } \\
\text { methods and protocols } \\
\text { (e.g. BIMex, Sec.F-O; } \\
\text { TIDP/MIDP in BEP) }\end{array}$ & \multicolumn{10}{|c|}{$\begin{array}{l}\text { Agree on the methods and protocols for storing, accessing, and modifying } \\
\text { project files and documents. For example, file areas in your common data } \\
\text { environment (CDE); agreed file naming convention and the version control. }\end{array}$} \\
\hline $\begin{array}{l}\text { *Updated collaboration } \\
\text { (BIM) plan }\end{array}$ & \multicolumn{10}{|c|}{$\begin{array}{l}\text { Update your planned task durations with actual to be able to compare your } \\
\text { plan against the realization of the plan (as-plan vs. as-is). Include these } \\
\text { different stages of the plan in your final report. }\end{array}$} \\
\hline $\begin{array}{l}\text { Design process and } \\
\text { coordination }\end{array}$ & \multicolumn{10}{|c|}{$\begin{array}{l}\text { Initial clash analysis, design process, quality check and assurance, } \\
\text { production of coordinated models in an open sharable format }\end{array}$} \\
\hline $\begin{array}{l}\text { Project completion, } \\
\text { reporting and delivery }\end{array}$ & \multicolumn{10}{|c|}{$\begin{array}{l}\text { Finalize the report, including the updated BIM execution plan(s). Finalize the } \\
\text { project files to be shared with the client. Reflect on your collaboration } \\
\text { process and effectiveness. }\end{array}$} \\
\hline Presentation & \multicolumn{10}{|c|}{$\begin{array}{l}\text { Document your collaborative process, outcomes and lessons learned to } \\
\text { present in class on the last day }\end{array}$} \\
\hline *interim deliverables & \multicolumn{10}{|c|}{ Remarks } \\
\hline
\end{tabular}




\subsection{Structuring, supporting and assessing teamwork}

Given that students often consider aspects of group work to be challenging, unsatisfying and unfair due to uneven workloads or negative group dynamics, we drew upon studies of group work (Boud et al. 1999; Dochy et al. 1999; Kriflik and Mullan 2007) and continuous assessment (Christoforou and Yigit 2008; Tuunila and Pulkkinen 2015), and employed several strategies including: 1) allowing students to self-select some team members based on mutual expectations, ethics and performance goals; 2) suggesting general project roles to help in planning tasks, but making space for students to learn to negotiate the division of work and responsibilities; 3 ) incorporating interim progress meetings with each group and facilitating discussion among team members, and 4) using self- and peer-evaluations to address any discontent among team members. The message we made clear throughout the course and especially during our clientteam meetings was that the teams that support each other tend to be more successful.

In order to implement PDCA cycles, we met with each of the teams in Week 4 and then again in Week 8 to discuss their initial and updated plans respectively. During these meetings, teams were also asked to complete an informal survey to gauge their level of confidence in understanding the required work and their ability to complete and deliver this work on deadline (Table 2). The survey served to further inform and structure the discussion among team members and address any initial sources of confusion, concerns, or lack of clarity.

Table 2. Team self-assessment surveys for informing the team discussions during client-teams consultations.

\begin{tabular}{|c|c|}
\hline First meeting & Second meeting \\
\hline How many times did your group meet so far? & What is the completion stage (in \%) of your project? \\
\hline What are your group goals for delivering the project? & $\begin{array}{l}\text { Is your project (behind schedule; on time; ahead of schedule; } \\
\text { not sure)? }\end{array}$ \\
\hline What responsibilities have you identified so far? & What resources did you use to develop your plan? \\
\hline \multicolumn{2}{|l|}{ Which major milestones have you established? } \\
\hline \multicolumn{2}{|l|}{ What types of tasks were you able to allocate so far? } \\
\hline $\begin{array}{l}\text { How confident (1-not at all; } 5 \text {-very confident) are you at } \\
\text { this stage in terms of: } \\
\text { - Clarity of work } \\
\text { - Scope of work } \\
\text { - Ability to do the work } \\
\text { - Ability to complete the work on time }\end{array}$ & $\begin{array}{l}\text { How confident (1-not at all; 5-very confident) are you at this } \\
\text { stage in terms of: } \\
\text { - Clarity of work } \\
\text { - Scope of work } \\
\text { - Ability to do the work } \\
\text { Rate your team's plan (1-not at all; 5-very much) for: } \\
\text { - Clarity } \\
\text { - Usefulness }\end{array}$ \\
\hline $\begin{array}{l}\text { What is your strategy for checking and monitoring the } \\
\text { work and progress of your team? }\end{array}$ & $\begin{array}{l}\text { What were the major changes (if any) to your initial plan } \\
\text { given your work progress to date? Why? }\end{array}$ \\
\hline $\begin{array}{l}\text { What resources have you consulted so far for planning } \\
\text { your work? }\end{array}$ & $\begin{array}{l}\text { What were the major challenges in the process of planning } \\
\text { and delivering the work so far? Why? }\end{array}$ \\
\hline $\begin{array}{l}\text { What capabilities, skills or resources do you think you } \\
\text { need to progress the work? }\end{array}$ & $\begin{array}{l}\text { How would you overall describe the effectiveness of your } \\
\text { team collaboration so far? }\end{array}$ \\
\hline
\end{tabular}


This approach served as an integral part of stimulating team reflections throughout the course and promoting incremental improvement in the development of the initial and updated BEPs. The formal assessment focused on the final BEP the teams presented on the last day of class, along with their lessons learned. Each group was left to its own discretion in structuring and formatting these reports and in the extent to which they considered BIM guidelines and templates. However, at a minimum, all reports had to include the record of updated roles, responsibilities, tasks, milestones, file management procedures and a communication strategy. Here, our overarching goal was to capture the evolution in each team's approach to delivering the project as a basis for reflection.

The critical component of this problem-based learning was the individual reflection. This individual assignment, which was submitted following the group work, served to assist students in identifying challenging instances in their collaborative experience and establishing relevance to the professional competencies for future action. Specifically, students were asked to reflect on the decisions they made during the group project, evaluate how well they worked, what role or value the BIM guidelines played in the process, and what they would do differently next time. This metacognitive approach follows the literature on guided reflection in experiential learning concepts (Rosier 2002; Schön 2010). The primary goal of a written reflection is to help students develop an awareness of their own thoughts about a situation and encourage the transfer of learning to the workplace by recognizing areas for improvement.

\section{Findings and lessons learned}

Overall, the results illustrate a rich picture of the complexity of planning and implementing a classroom-based BIM information delivery process. Moreover, what also emerged was the value of teaching students to observe, reflect and act upon information that they find challenging. While implementing BIM approaches is often complicated, we structured this learning process by encouraging student teams to step through an iterative plan-do-check-act cycle. Importantly, this approach demonstrated the value of an outcome-based method whereby the BEP and model deliverables served only as vehicles to encourage students to take ownership of their learning process and to test and apply a range of skills by making them more explicit. One overarching conclusion that emerged is that creating a BEP is only valuable when a shared understanding of its purpose and relevance is evident to students. Here, we observed several key aspects of how students went about unpacking this process.

\section{Embarking on a collaborative planning process}

Given that this course presents what is essentially a management challenge, students tend to initially perceive it as a "black box". While the assignment deliverables (i.e. the models and reports) are well-defined, the process students need to plan and manage in producing those deliverables is far from clear. Moreover, making the process explicit for students makes this problem-solving activity particularly challenging and one they seem rarely asked to perform. 
For all years, in the early stages of the process, all teams struggled in identifying the scope of work before outlining the required tasks and allocating these tasks to qualified team members. Their assumed roles tended to be discipline-focused and based on the model files the teams were provided (e.g. architectural, structural, mechanical, etc.), while their responsibilities often appeared to be vaguely defined and mostly limited to model authoring. Similarly, the students framed the initial goals and milestones as to adhere to the requirements of their final deliverables. Finally, documenting these decisions meant also customizing the BEP templates to make the plan logical and easy to follow.

The first progress check revealed that the teams tended to spend more time on developing and populating the BEP templates than in actually planning their work. This indicated that the teams were only beginning to familiarize with the content of BEP without yet defining their collaboration goals and strategies. For example, some teams left many tables and sections of their BEP empty, while others filled them with generic information that did not apply to their work (e.g. project cost, or construction schedule). However, we anticipated this and took measures to avoid the perception that putting BEP together was a mere form-filling exercise. Thus, a major steering point for all teams was to understand the information requirements first and then customdesign their BEPs before gradually expanding their plans to reflect new information, tasks and responsibilities. In other words, we suggested that the teams include only information that was clear to all group members at all times in terms of purpose and procedures.

During our team discussions, we asked students to complete the aforementioned informal survey (see Table 2). Although the BEP as a single document suggests a consensus in group thinking, the student responses at times revealed confusion and uncertainty about their roles and responsibilities. This was largely evident in relatively low student ratings of their own clarity on the scope of work and ability to complete tasks on time. This level of uncertainty varied both within and across all of the teams.

Fortunately, this presented us with an opportunity to guide the students in discussing the reasons for disparities in their views, expectations and confidence levels. In our conversations, some students stated that their low confidence levels were a result of not carefully reading the assignment brief, while others stated a lack of technical skills and general tendency to procrastinate. Here, our task was to encourage the students to address these issues by facilitating conversations about the strengths and weaknesses of their members and to address any grievances by planning their work with clearer expectations. Thus, another finding at this stage was the importance of encouraging team members to support their peers and thus collaborate, rather than simply cooperate.

\section{Progressing and updating plans}

The second progress check revealed how teams began to diverge in their collaborative approaches and pose more focused and informative questions. At this stage, the teams had largely expanded their initial plans, identified a variety of approaches in adapting the standards and guidelines and developed their own means of representing their plans, methods and procedures. Compared to their initial plans, project goals became more meaningful to the teams as some aimed to improve the effectiveness of their respective collaborative strategies, improve their communication and reduce errors in their designs. 
Moreover, now emboldened with their initial modeling and clash analyses, the students updated and expanded their roles and responsibilities based on the newfound knowledge of their skills. This learning curve was evident for all teams after they began to understand the skill levels of their members and to adjust their work allocation. At this stage, they recognized the responsibilities for performing clash detections, producing reports, setting up data environments, coordinating file exchanges and scheduling meetings. Many teams reported increasing the meeting frequency to several times a week and some began to include weekly schedules and progress reports along with their status checks.

During this second round of discussions, we again asked students to complete an informal survey (see Table 2), this time to gauge their perceptions regarding project progress, confidence levels and the effectiveness of their collaborations to this point. The majority reported confidence levels slightly higher (i.e. 3-4), however, those students who still lacked confidence now attributed this to either the required technical skills or to facing deadlines in other courses. Again, this presented an opportunity for us to guide teams in engaging in more transparent discussions around availability and commitment to the project. This allowed the teams to review how they allocated tasks and build redundancy into their strategies to better avoid single points of failure.

What differentiated this second progress review from the first was that teams posed far more focused questions about their approaches to implementing their processes. In addressing these questions, we often took a Socratic approach, responding with reflective questions such as: "Why did you decide to do it that way?" "What information did you use in the process?" "What do you think would happen if...?" and "How did you agree on this procedure?". Here, our objective was to assist students in arriving at their own conclusions by articulating the rationales for their decisions (e.g. choice of file-sharing platform, working individually vs. concurrently, perceived risks, or referencing files without duplication and file review responsibilities) and why they deemed certain approaches to be more viable than others. In one instance, we conducted an interesting discussion with a team who decided simply to copy and paste the systems from an adjacent hospital wing into the unfinished wing because they thought that fixing any existing clashes would be easier than developing a strategy to design those systems anew. However, the team soon realized that checking and resolving hundreds of clashes, even in a single wing was far more tedious and taxing to be deemed an effective approach.

\section{Completion and reflection}

In all cases, these progress sessions helped the teams to produce final models and BEP documents of consistent quality. This suggests that despite some initial confusion and general frustration, all students fulfilled the objectives of developing a BEP by (i) defining and allocating project and information delivery responsibilities; (ii) identifying file management procedures, information workflows and tasks with estimated durations; and (iii) executing, updating and reflecting on applied collaboration, communication and technology strategies. By contrast, while the project results were consistent, the reflective accounts revealed a broad range of insight into the students' learning and decision making processes and important considerations about what they would have done differently.

In terms of the BEP format, students applied and adapted the BIM standards and guidelines in different ways, often creating a hybrid by creating their own tables, graphs and charts. In 
particular, they noted the straightforwardness of the US BIMex approach to defining goals, uses and priorities, and the UK's BS1192 and PAS1 192 more specific guidelines for managing file exchanges through CDE. For planning activities, some groups took a process modeling approach, while others used Gantt charts and tables to communicate the deliverables and deadlines.

However, in all years, information management approaches -including understanding the purpose of specific standards, methods and procedures, such as those pertaining to file naming and sharing - varied greatly across the teams. While all of the teams designed their CDEs by referencing BS1192, some teams created additional custom folders to visualize how their information moved from one content area to another (e.g. from Work-In-Progress area to the "check-and-verify" before moving to the team-Shared area), while others intuited that BS1192 content areas only applied to the model files.

With respect to file naming, all teams developed their own conventions that were also largely drawn from BS1192. However, teams quite often used these conventions inconsistently. For example, some teams only applied naming conventions to model files, but not to other documents. In other cases, teams did not adhere to their conventions at all, although their BEPs stated otherwise. Here, one possible explanation may lie in how students allocated modeling and management responsibilities. Teams that we surmise were more risk-averse allocated most of their modeling tasks to a few skilled members, which suggests that only one or two people produced those files. In such cases, students may have resorted to familiar practices, especially if the role of checking for compliance was undefined or non-existent. Students who worked in teams with more articulated and distributed sets of responsibilities for sharing files commented that the moment they realized they needed to agree on a file-naming convention was when the number of files began rapidly to increase. This illustrates possible challenges in adopting these conventions when there is little understanding of the consequences for not adhering to them.

\section{Student reflections on the collaborative experience}

A critical aspect of this problem-based learning experience lies in making sense of the students' strategies and challenges to ensure the transferability of lessons learned and skills deemed critical for delivering well-coordinated BIM projects. Thus, after the project was complete, we asked the students to reflect on their perceptions of their collaborative successes and shortcomings, how they addressed any challenges, and how the BIM standards and guidelines helped to inform their work. Using heuristics, we analyzed the reflective reports and grouped their observations into three domains: 1) scope of work (i.e. process planning and implementation); 2) communication and management (i.e. managing activities and teamwork); and 3) practical skills (i.e. technological considerations that shaped decisions and outcomes).

Defining the scope of work was a notable challenge. Many students stated that the project was marked by a sense of confusion, a feeling of being overwhelmed with not knowing how to begin and proceed and a desire for clarity about assignment expectations. As we designed the project to be open-ended, this suggests that the uncertainty and latitude many students experienced provoked a sense of discomfort. For them, tackling this complexity began with defining basic discipline roles and familiarizing themselves with the necessary documents and templates. All students indicated that assigning responsibilities was difficult and required a gradual mental shift from viewing these as discipline-based to more managerial and interdependent. For example, one 
student stated that at first the "roles were conventional, but not helpful". This shift occurred when the students realized that in addition to the modeling, other necessary responsibilities included organizing teams, scheduling meetings, tracking team progress, and managing information. It was typically at this point that students began to negotiate their team roles and responsibilities in greater detail in terms of their individual skills, preferences, strengths and weaknesses.

A sample of some student responses on this point:

"Our project team members did not contribute much time on fully familiarising with the requirement at the beginning."

"Roles and responsibilities were vaguely distributed; by discipline."

"Essential duties were fulfilled, although not necessarily by the correct person."

"When sharing responsibilities, every task (big or small, no underestimation) should be specified and given to a particular person(s)."

"Individuals unfamiliar with roles, processes or deliverables, could waste hours, producing little."

"Updating the BEP like many other tasks was open to everybody, whomever had the chance to do so. (...) Being that it was not assigned to a particular person(s), no one prioritised it."

The team management process largely involved planning project workflows and tracking each member's contributions. This often involved specifying activities, estimating task durations, tracking progress and enacting strategies to manage challenges. In this respect, in the beginning most students predicted (in what we would qualify as inherent optimism) that everything would run as planned and take less time than they anticipated. However, many students observed that they typically underestimated the durations they assumed for completing activities, which nearly always led to delays. Some of the reasons for these delays included inexperience in completing tasks (e.g. unfamiliarity with building systems, learning new software, loading large files, interpreting clash reports), working in a linear rather than a concurrent manner or simply not accounting for all tasks. In fact, some students reported that their teams developed their initial schedules without even checking the model files first. Other reasons for delays included lack of communication, reluctance to ask for help and poor time management skills, particularly with respect to deadlines for other coursework.

In response to these challenges, many students emphasized that frequent meetings were critical in addressing such issues, reallocating responsibilities and making collective decisions. In addition, some students recognized that the reluctance of a few of their colleagues to learn the necessary software and perform the modeling work led to greater reliance on other more knowledgeable members, which posed a greater risk of delays. For example, as some of the architecture students were unfamiliar with Revit, the construction students assumed some of the modeling tasks because they perceived this to be faster than having the architecture students learn the software.

A sample of student responses further illustrates these observations: 
"In retrospect, project members should be eager to learn to embrace new technology adapting the changing nature in short time."

"There is direct correlation between attitudes of participants and the success of projects."

"Project members should accept a new challenge and have the willingness to improve."

"Based on our experience, regular meetings are essential for BIM projects."

"There were 10 weeks to get things done but we had an illusion of having more than enough time and got ahead of our reality. That illusion sadly lasted until the end, then we rushed things."

"Time estimations were based on meeting the deadline, rather than the actual amount of time we believe it would take to successfully carry them out."

"Due to time constraints in the last stages, our standard dropped from the best to decent."

Finally, technology-related issues undoubtedly shaped some of the students' experiences in a variety of ways. Apart from qualifying some of their software skills as insufficient, some students stated that managing the technology aspect meant understanding access to resources, file storage capacity and technology appropriateness for the given tasks. Some of these challenges were evident in choosing between Solibri and NavisWorks for handling IFC files, or checking for clashes. One common student observation concerned the sheer number of clashes that were found in the source files, a challenge that then took time to work through to understand which were the most consequential for their design strategies. In addition, none of the teams considered the time and skills required to produce IFC files, which resulted in deliverables that were either missing data or misaligned. Still, some teams reported that they explored tools and platforms beyond those we introduced, such as A360 for file management or using the LOD Planner ${ }^{3}$ and NBS BIM Toolkit ${ }^{4}$ for support in producing their BEPs.

To conclude, we summarize these and other student observations into the set of skills and considerations for addressing the collaboration challenges (Table 3).

Table 3: Students' reflection: considerations for effective collaboration.

\begin{tabular}{lll}
\hline Skills needed & Improvement strategies & Challenges \\
\hline Time management & Team's workloads and schedule & Guidelines complexity \\
Accountability & Meeting strategy & Technology issues \\
Positive attitude & Adequate task allocation & Resource logistics \\
Commitment & Task prioritization & Software training \\
Technical confidence & Task time estimates & Enforcing team deadlines \\
Knowing own strengths & Time allocation for brainstorming & \\
\hline
\end{tabular}

\footnotetext{
3 https://www.lodplanner.com

4 https://toolkit.thenbs.com
} 


\section{Discussion}

We drew several key findings as implications for teaching BIM as a collaborative information delivery process.

Most BIM teaching approaches focus on delivering complex project models informed by BIM execution planning guides (e.g. Beauregard et al. 2016; Solnosky et al. 2015) and technologies (Peterson et al. 2011; Plume and Mitchell 2007), often prioritizing design and project management techniques focused on project metrics such as cost or time. By contrast, we approached teaching BIM primarily as a team-coordinated information management process bound by BIM standards and procedures documented in a BEP. The technology and modeling work served only as a means for testing and achieving an integrated and coordinated delivery process. The limited scope of model-based work that we adopted can encourage the flow of a plan-do-check-adjust cycle, as the use of complex industry projects in the classroom can often overwhelm students with modeling and interrogation work at the expense of learning objectives and gains (Puolitaival and Forsythe 2016) and complex BIM standards and procedures add to the already difficult task of conceptualizing what effective collaboration entails. Undergraduate students understandably lack discipline-specific knowledge of construction systems and processes (Puolitaival and Forsythe 2016) so applying BIM and lean thinking concepts to their own delivery processes and reflecting on the outcomes can encourage students to pose important questions and recognize considerations about effective collaboration.

Designing and implementing a collaborative information delivery strategy is a complex problem-solving activity that most students initially tend to perceive as a black box. In our experience, students begin to unpack this box by adopting discipline-specific roles (e.g. architect, mechanical engineer, or BIM manager) and defining tasks, crudely at first, but with more detail and relevance over time as they iterate through stages of planning and feedback. However, the evolution of student roles and responsibilities on our project suggests that these roles are often seen through the technology lens and thus not a very useful concept as they are bound to change in response to technological transformations (Succar et al. 2013). Instead, roles should give way to clearer individual responsibilities as building blocks for team capabilities. It is through this realization that our students have recognized a more useful set of responsibilities and skills, resembling those of BIM competencies (Rahman et al. 2019; Succar et al. 2013). For example, students observed that while technical skills are important, far more challenging were issues of accountability, disposition, or transparency about own skills and strengths, difficulties in managing team members' input (Poerschke et al. 2010), and setting performance expectations. These link to and extend some of the primary competencies described by Succar et al. (2013), such as managerial (i.e. decision-making ability driving selection of strategies), and functional (i.e. ability to manage and deliver projects).

Related to these managerial and functional competencies, students also tend to approach planning collaborative information delivery with the expectation and optimism that few things will go wrong, which we attribute to a lack of experience. And yet, underestimating the time or scope of work is inseparable from managing expectations and learning how to communicate and resolve delays when internally set deadlines are missed. Being transparent and explicit about the assumptions is fundamental, but the assumption that these aspects of project work are intuitively 
clear is prevalent. As a result, developing and agreeing to a plan did not necessarily guarantee adhering to it.

Interestingly, the use of technology, often considered an important facet of executive skills (Succar et al. 2013), served as a platform for revealing two distinct collaboration strategies that our teams adopted: one that was risk-averse and engaged only skilled team members in modeling activities, and a second, more expansive path in which all team members took the initiative in learning new applications in order to complete tasks. As discussed previously, we often emphasized the importance of process over product in our course, but those who were risk-averse nonetheless tended to focus on producing good models, which often meant working linearly and individually, shifting the workload to fewer members and resorting to familiar practices. By contrast, those teams who fully embraced the challenge invested time in learning new tools, distributed their work more evenly, shared responsibilities and made more decisions as a group. Thus, we could say that in this case good model outputs were not necessarily indicative of good collaborative processes. This collaboration effectiveness was not measured in any quantifiable manner, but the overall positive student experience with group work at the end of the course over the past three years suggests that even in cases in which teams did not fully collaborate, students felt more empowered by learning what makes collaboration successful.

These observations and student reflections raise important implications for teaching BIM as a process-improvement methodology (Wang and Leite 2014) and question if instructors require technical expertise to teach BIM competencies. In this study, BIM standards underpinned the BEP development as a collaborative framework, but our results suggest that what students include in their BEP may mean little unless it is relevant and meaningful to their own experience. Overall, one demonstrably valuable result of this study was that supporting and mentoring teams in engaging in constructive conversations about what effective collaboration means to them and adapting BIM guidelines as instruments in formalizing their collaborative plans. Such illstructured problems require and benefit from continuous improvement assessment strategies in which team-based self-assessment surveys and reflective accounts serve to contextualize experiences into transferable professional skills. This means that through planning and reflecting on their collaborative process, students can begin to contextualize and understand BIM standards and templates

\section{Conclusions}

In this case study, we investigated how students learn BIM methods and strategies in the context of collaborative project planning. Unlike most approaches to teaching BIM that focus on quality, cost or time performance metrics for technology-driven project delivery, we concentrated on how teams consider collaboration and information management processes through employing BIM standards and guidelines. Our investigation of this team-based learning process through a PDCA cycle yielded several conclusions for teaching collaborative information management strategies:

1) Prioritizing the quality of an information delivery process, rather than a final product, can help students learn collaboration techniques and strategies informed by BIM standards; 
2) Reducing the scope of modeling and analysis work on a course project can serve as a more effective vehicle for testing collaborative strategies and identifying associated risks and tradeoffs;

3) Defining responsibilities, rather than roles, is a useful approach for students in identifying competencies for coordinated information delivery; and

4) Reflection and active support in continuous improvement are critical in helping students to contextualize their own collaborative experience for broader BIM industry practice.

Overall, the process demonstrated the value of an outcome-based and process-focused approach that underscores the social aspects of collaborative work to be as important as technological knowledge. Teaching industry-oriented process-planning methods for collaborative information delivery is firmly nested within teaching management and communication skills, and understanding the possible reasons for the given outcomes is more informative than the final product itself. To support students in meaningfully navigating the ever changing BIM guidelines, we suggest a strategy where students start by prioritizing what they see as relevant and then explore effective means for visualizing their collaborative strategy. Allowing students to make mistakes is crucial in developing the process knowledge where project management and team management skills become more explicit in their importance for successful BIM implementation. This problem-based approach carries broader implications to similar initiatives around teaching collaborative BIM, which is an intensive field that should allow students to internalize, apply and evaluate BIM strategies that resonate with their experience. And while a single elective course remains an insufficient educational model for effectively addressing both the technical and social aspects of interdisciplinary BIM information delivery, it offers a practical platform to address BIM competencies that are applicable beyond what is traditionally defined as BIM.

\section{References}

Abdirad, H., and Dossick, C. S. (2016). "BIM curriculum design in architecture, engineering, and construction education: a systematic review." Journal of Information Technology in Construction (ITcon), 21(17), 250-271.

Ayer, S. K., Cribbs, J., Hailer, J. D., and Chasey, A. D. (2015). "Best Practices and lessons learned in BIM Project Execution Planning in Construction Education." Proceedings of 9th BIM Academic Symposium and Job Task Analysis Review, Washington, DC, 167174.

Beauregard, M., Alsafouri, S., and Ayer, S. (2016). "Development of a peer review-based activity to improve students bim process mapping understanding." 10th BIM Academic Symposium \& Job Task Analysis Review, Orlando, FL, 4-5 April, 27.

Becerik-Gerber, B., Ku, K., and Jazizadeh, F. (2012). "BIM-Enabled Virtual and Collaborative Construction Engineering and Management." Journal of Professional Issues in Engineering Education and Practice, 138(3), 234-245.

Boud, D., Cohen, R., and Sampson, J. (1999). "Peer Learning and Assessment." Assessment \& Evaluation in Higher Education, 24(4), 413-426. 
Bozoglu, J. (2016). "Collaboration and coordination learning modules for BIM education." Journal of Information Technology in Construction (ITcon), 21(10), 152-163.

Brooks, J. G., and Brooks, M. G. (1999). In search of understanding: the case for constructivist classrooms. Association for Supervision and Curriculum Development, Alexandria, VA.

Cabinet Office. (2011). Government Construction Strategy. Cabinet-Office London.

Christoforou, A. P., and Yigit, A. S. (2008). "Improving teaching and learning in engineering education through a continuous assessment process." European Journal of Engineering Education, 33(1), 105-116.

Cobb, P., Jackson, K., Smith, T., Sorum, M., and Henrick, E. (2013). "Design research with educational systems: Investigating and supporting improvements in the quality of mathematics teaching and learning at scale." National Society for the Study of Education Yearbook, 112(2), 320-349.

Cole, J. S., and Spence, S. W. T. (2012). "Using continuous assessment to promote student engagement in a large class." European Journal of Engineering Education, 37(5), 508525.

Crawshaw, D. T. (1976). Coordinating working drawings. Building Research Establishment, Current Paper CP 60/76, Watford, UK.

Dainty, A., Leiringer, R., Fernie, S., and Harty, C. (2015). "Don't believe the (BIM) hype: the unexpected corollaries of the UK'BIM revolution'." Engineering Project Organizations Conference, The University of Edinburgh, Scotland, UK.

Deming, W. E. (2018). The new economics for industry, government, education. MIT press.

Dochy, F., Segers, M., and Sluijsmans, D. (1999). "The use of self-, peer and co-assessment in higher education: A review." Studies in Higher Education, 24(3), 331-350.

Dossick, C. S., and Neff, G. (2011). "Messy talk and clean technology: communication, problemsolving and collaboration using Building Information Modelling." The Engineering Project Organization Journal, 1(2), 83-93.

Dubler, C. (2011). "Evaluating waste associated with building information exchange using lean theory." Doctoral Thesis, The Pennsylvania State University, University Park, PA, USA.

Egan, J. (1998). Rethinking construction. the report of the Construction Task Force to the Deputy Prime Minister, John Prescott, on the scope for improving the quality and efficiency of UK construction, Department of the Environment, Transport and the Regions, London.

Forbes, L. H., and Ahmed, S. M. (2011). Modern construction. CRC Press,.

Fruchter, R. (2001). "Dimensions of teamwork education." International Journal of Engineering Education, 17(4/5), 426-430.

Fruchter, R. (2003). "Innovation in engaging learning and global teamwork experiences." Towards a Vision for Information Technology in Civil Engineering, 1-13.

Henderson, L., and Jordan, N. L. (2009). "A modest proposal for a transdisciplinary curriculum for the design, construction, management and maintenance of architecture." Journal of Building Information Modelling, 35-37.

Hernández, R. (2012). "Does continuous assessment in higher education support student learning?" Higher education, Springer, 64(4), 489-502.

Hmelo-Silver, C. E. (2004). "Problem-Based Learning: What and How Do Students Learn?" Educational Psychology Review, 16(3), 235-266. 
HMGovernment. (2012). "Industrial strategy: government and industry in partnership." www.bis.gov.uk, 22.

Hoang, H., Huang, M., Sulcer, B., and Yesilyurt, S. (2017). "Carnegie Math Pathways 2015-2016 Impact Report: A Five-Year Review. Carnegie Math Pathways Technical Report.” Carnegie Foundation for the Advancement of Teaching, ERIC.

Holland, R., Messner, J., Parfitt, K., Poerschke, U., Pihlak, M., and Solnosky, R. (2010). "Integrated Design Courses Using BIM as the Technology Platform." In Implementing BIM into Higher Education Curriculum, National institute of Building Sciences, Annual Meeting: EcoBuild America Conference, Washington, DC, 2010

Isaksson, S. (2008). "Assess as you go: the effect of continuous assessment on student learning during a short course in archaeology." Assessment \& Evaluation in Higher Education, Taylor \& Francis, 33(1), 1-7.

Kalay, Y. E. (2001). "Enhancing multi-disciplinary collaboration through semantically rich representation." Automation in Construction, Design Representation, 10(6), 741-755.

Kitchner, K. S. (1983). "Cognition, Metacognition, and Epistemic Cognition.” Human Development, 26(4), 222-232.

Kolb, D. A. (1984). Experiential Learning: Experience as the Source of Learning and Development. Prentice-Hall, Inc., Englewood Cliffs, N.J.

Koskela, L. (2000). An exploration towards a production theory and its application to construction. VTT Technical Research Centre of Finland.

Koutsabasis, P., Vosinakis, S., Malisova, K., and Paparounas, N. (2012). "On the value of Virtual Worlds for collaborative design." Design Studies, 33(4), 357-390.

Kriflik, L., and Mullan, J. (2007). "Strategies to Improve Student Reaction to Group Work." Journal of University Teaching and Learning Practice, 4(1), 13-27.

Kronholm, M. M. (1996). "The impact of developmental instruction on reflective judgement." Review of Higher Education, 19(2), 199-225.

Ku, K., and Taiebat, M. (2011). "BIM Experiences and Expectations: The Constructors' Perspective." International Journal of Construction Education and Research, 7(3), 175197.

Landscape Institute (Ed.). (2016). BIM for landscape. Routledge, London.

Latham, S. M. (1994). "Constructing the team." The final report of the government/industry review of procurement and contractual arrangements in the UK construction industry HMSO, London.

Macdonald, J. A. (2012). "A framework for collaborative BIM education across the AEC disciplines." 37th Annual Conference of Australasian University Building Educators Association (AUBEA), Sydney, Australia.

Messner, J., Anumba, C., Dubler, C., Goodman, S., Kreider, R., Leicht, R., Saluja, C., and Zikic, N. (2020). BIM Project Execution Planning Guide, Version 3.0. Computer Integrated Construction Research Program, The Pennsylvania State University, University Park, PA, USA.

Morris, A. K., and Hiebert, J. (2011). "Creating shared instructional products: An alternative approach to improving teaching." Educational Researcher, SAGE Publications Sage CA: Los Angeles, CA, 40(1), 5-14. 
O’Brien, W., Soibelman, L., and Elvin, G. (2003). "Collaborative design processes: an active-and reflective-learning course in multidisciplinary collaboration." Journal of Construction Education, 8(2), 78-93.

Perrenet, J. C., Bouhuijs, P. A. J., and Smits, J. G. M. M. (2000). "The Suitability of Problembased Learning for Engineering Education: Theory and practice." Teaching in Higher Education, 5(3), 345-358.

Perry, W. G. (1999). Forms of Intellectual and Ethical Development in the College Years: A Scheme. Jossey-Bass Higher and Adult Education Series. Jossey-Bass Publishers, 350 Sansome St.

Peterson, F., Hartmann, T., Fruchter, R., and Fischer, M. (2011). "Teaching construction project management with BIM support: Experience and lessons learned." Automation in Construction, Building Information Modeling and Changing Construction Practices, 20(2), 115-125.

Plume, J., and Mitchell, J. (2007). "Collaborative design using a shared IFC building modelLearning from experience." Automation in Construction, CAAD Futures, 2005, 16(1), $28-36$.

Poerschke, U., Holland, R. J., Messner, J. I., and Pihlak, M. (2010). "BIM collaboration across six disciplines." Proceedings of the International Conference on Computing in Civil and Building Engineering, Nottingham, 575-671.

Prados, J. W., Peterson, G. D., and Lattuca, L. R. (2005). "Quality assurance of engineering education through accreditation: The impact of Engineering Criteria 2000 and its global influence." Journal of Engineering Education, Wiley Online Library, 94(1), 165-184.

Puolitaival, T., and Forsythe, P. (2016). "Practical challenges of BIM education." Structural Survey, Emerald Group Publishing Limited, 34(4/5), 351-366.

Rahman, R. A., Ayer, S. K., and London, J. S. (2019). "Applying problem-based learning in a building information modeling course." Int. J. Eng. Educ, 35(3), 956-967.

Rosier, G. (2002). "Using reflective reports to improve the case method." Journal of Management Development, 21(8), 589-597.

Salner, M. (2011). "Adult cognitive and epistemological development in systems education." Systems Research, 3(4), 225-232.

Sancho-Thomas, P., Fuentes-Fernández, R., and Fernández-Manjón, B. (2009). "Learning teamwork skills in university programming courses." Computers \& Education, 53(2), 517-531.

Schön, D. A. (2010). "Educating the reflective practitioner: Toward a new design for teaching and learning in the professions." Australian Journal of Adult Learning, 50(2), 448-451.

Seed, W. R. (2015). "Transforming design and construction: A framework for change." Arlington, VA: Lean Construction Institute.

Shelbourn, M., Macdonald, J., McCuen, T., and Lee, S. (2017). "Students' perceptions of BIM education in the higher education sector: A UK and US perspective." Industry and Higher Education, 31(5), 293-304.

Solnosky, R., Parfitt, M. K., and Holland, R. (2015). "Delivery methods for a multi-disciplinary architectural engineering capstone design course." Architectural Engineering and Design Management, 11(4), 305-324. 
Succar, B., and Sher, W. (2014). "A Competency Knowledge-Base for BIM Learning." Australasian Journal of Construction Economics and Building - Conference Series, 2(2), $1-10$.

Succar, B., Sher, W., and Williams, A. (2013). "An integrated approach to BIM competency assessment, acquisition and application." Automation in Construction, 35, 174-189.

Sutrisna, M., and Goulding, J. (2019). "Managing information flow and design processes to reduce design risks in offsite construction projects." Engineering, Construction and Architectural Management, Emerald Publishing Limited, 26(2), 267-284.

Tichnor-Wagner, A., Wachen, J., Cannata, M., and Cohen-Vogel, L. (2017). "Continuous improvement in the public school context: Understanding how educators respond to plan-do-study-act cycles." Journal of Educational Change, 18(4), 465-494.

Tribelsky, E., and Sacks, R. (2010). "Measuring information flow in the detailed design of construction projects." Research in Engineering Design, 21(3), 189-206.

Trotter, E. (2006). "Student perceptions of continuous summative assessment." Assessment \& Evaluation in Higher Education, Taylor \& Francis, 31(5), 505-521.

Tuunila, R., and Pulkkinen, M. (2015). "Effect of continuous assessment on learning outcomes on two chemical engineering courses: case study." European Journal of Engineering Education, Taylor \& Francis, 40(6), 671-682.

UK BIM Task Group. (2014). U.K. BIM Task Group: A UK Government Initiative. http://www.bimtaskgroup.org.

Walker, A., Leary, H., and Hmelo-Silver, C. E. (2015). Essential readings in problem-based learning. Purdue University Press, West Lafayette, Indiana, USA.

Wang, L., and Leite, F. (2014). "Process-oriented approach of teaching building information modeling in construction management." Journal of Professional Issues in Engineering Education and Practice, American Society of Civil Engineers, 140(4).

Witmer, D. F. (1998). "Introduction to computer-mediated communication: A master syllabus for teaching communication technology." Communication Education, 47(2), 162-173.

Womack, J. P., and Jones, D. T. (1997). "Lean thinking: banish waste and create wealth in your corporation." Simon \& Schuster, New York.

Wu, W., and Hyatt, B. (2016). "Experiential and Project-based Learning in BIM for Sustainable Living with Tiny Solar Houses.” Procedia Engineering, ICSDEC 2016 - Integrating Data Science, Construction and Sustainability, 145, 579-586. 